\title{
A method to consider the nonlinear behaviour of reinforced concrete in flexible earth-retaining walls: preliminary results
}

\author{
J. Cândido Freitas \\ CONSTRUCT, Faculty of Engineering (FEUP), University of Porto, Porto, Portugal \\ Superior Institute of Engineering (ISEP), Polytechnic Institute of Porto, Porto, Portugal \\ M. Matos Fernandes \& M. A. C. Ferraz \\ CONSTRUCT, Faculty of Engineering (FEUP), University of Porto, Porto, Portugal
}

J. C. Grazina

Faculty of Science and Technology (FCTUC), University of Coimbra, Coimbra, Portugal

\begin{abstract}
This paper presents a numerical methodology to incorporate in finite element analyses of deep excavations the nonlinear behaviour of reinforced concrete walls. This method is based on the interaction between two well validated numerical models: one used for incremental analysis of geotechnical works (but assuming concrete as linear elastic) and the other used for nonlinear analysis of reinforced concrete structures taking into account the characteristics of the concrete and the steel reinforcement at each structural section. The analysis of an excavation in clay supported by a single propped diaphragm wall is presented as an example of application. It is shown how the consideration of the nonlinear behaviour of reinforced concrete influences the global performance of the retaining structure.
\end{abstract}

\section{INTRODUCTION}

Deep excavations in urban areas are usually supported by diaphragm or pile walls made of reinforced concrete (Liu et al., 2011; Ng et al., 2012; Finno et al., 2015).

The interaction between such structures and the supported soil is quite complex because their configuration evolves as the construction progresses and their deformations influence the magnitude and the distribution of the earth pressures and of the structural stresses.

The understanding of this problem has been considerably enhanced, from the late 1970s onward, by the use of finite element models (Clough and Tsui, 1974; Finno and Harahap, 1991; Matos Fernandes et al., 1993; Zdravkovic et al., 2005; Schafer and Triantafylidis, 2006; Hashash et al., 2011; Burlon et al., 2013; Dong et al., 2016).

In spite of the increasing progress and sophistication of these models along the last decades, a linear elastic response for the reinforced concrete wall is usually assumed. However, since concrete has a relatively small tensile strength, its mechanical behaviour becomes nonlinear for values of the mobilized stresses quite below the correspondent limit stresses (Bazant and Parameshwara, 1977).

The nonlinear response of reinforced concrete, induced by cracking, has been intensively studied in structural engineering and reliable numerical models are available to deal with such behaviour (Crisfield, 1997; Mohr and Bairán, 2010).
This paper presents a simple numerical methodology to consider the nonlinear behaviour of reinforced concrete in finite element analyses of deep excavations. In spite of its simplicity, the procedure consists of an interaction of two relatively advanced models: a finite element model for incremental geotechnical analysis and a pure structural model for nonlinear analysis of reinforced concrete structures that takes into consideration the characteristics of concrete and of steel reinforcement at each section.

In order to illustrate its potential, the presentation of the proposed methodology is complemented with an example of application, an excavation supported by a single propped diaphragm wall.

\section{PROPOSED METHODOLOGY}

\subsection{General}

The basic idea, suggested by Matos Fernandes (2010), was to use a geotechnical finite element model (so-called model GEO) and a model dealing with the nonlinear behaviour of reinforced concrete (so-called model RC) just as they are, and to develop a new computer code in order to make the two models to work and interact in parallel.

As shown by Figure 1, for each stage of the simulation of the excavation by Code GEO, the computed bending moment and axial stress diagrams of the retaining wall are applied to the sections modelled by Code RC, which accounts for the actual steel reinforcement at each section. Code RC then 
calculates the strains and cracking in the reinforced concrete wall and the corresponding adjusted stiffness at each section, which is transmitted to Code GEO, using an adjusted deformation modulus, to be used in the next construction stage.

\subsection{Model GEO}

Code GEO is a typical FEM code used to model 2D (plane stress, plane strain and axisymmetric) and 3D geotechnical works. It was adapted from the code FEMEP, developed at the Universities of Porto and Coimbra, Portugal (Almeida e Sousa et al., 2011).

The code incorporates several types of finite elements, allowing the simulation of the ground mass, structures and the soil-structure interfaces; associated to each element there is a specific activation and deactivation criterion, so various construction phases can be considered separately and sequentially.

Problems can be analysed in terms of total or effective stresses, including excess pore pressure generation and consolidation through a coupled formulation of equilibrium and flow equations.

The code permits the consideration of several constitutive models to characterize the nonlinear behaviour of the soil and the soil-structure interface, as well as geometric nonlinearity. To account for the nonlinear behaviour, an iterative algorithm based on the modified Newton-Raphson method is activated.

\subsection{Model RC}

Code $\mathrm{RC}$ is a nonlinear code for reinforced concrete analyses, based on the 1970's classic fibre method (Cohn and Ghosh, 1972; Chen and Shoraka, 1974).
It corresponds to code FIBRAS, developed at the University of Porto using EVOLUTION framework (Ferraz, 2010).

In the fibre method, the moment-curvature relationship is obtained numerically by dividing the actual cross section into small elements called fibres (Figure 1) where uniaxial stress strain laws are used to describe the response of materials. Assuming that the section remains plane and normal to the longitudinal axis, the strain distribution over the section is linear, and consequently the strain on each fibre is related to the curvature of the section. Considering the nonlinear stress-strain relationships of concrete and reinforcing steel fibres into which each section is divided, the stresses are related to the applied bending moments and axial forces through the condition of equilibrium and are obtained using the tangent stiffness iterative step-by-step procedure.

An elastic-perfectly-plastic behaviour for compression and a model of tension stiffening for tension (Figure 2a) are considered for concrete, whereas a bilinear elasto-plastic behaviour (Figure $2 \mathrm{~b}$ ), both for tension and compression, is assumed for reinforcing steel.

The use of a tension stiffening model for tension in concrete is due to the fact that at a crack the full internal tensile force is carried by the reinforcement, whereas between cracks some amount of the tensile force is transferred through bond to the surrounding concrete. As a result, the reinforcement strains between cracks are smaller than the ones at the cracks. In brief, a cracked concrete member behaves as a member with a variable cross section, due to the highly reduced stiffness in the cracked zone. However, between the cracks the concrete in tension continues to contribute to the flexural stiffness, which reduces the curvature.

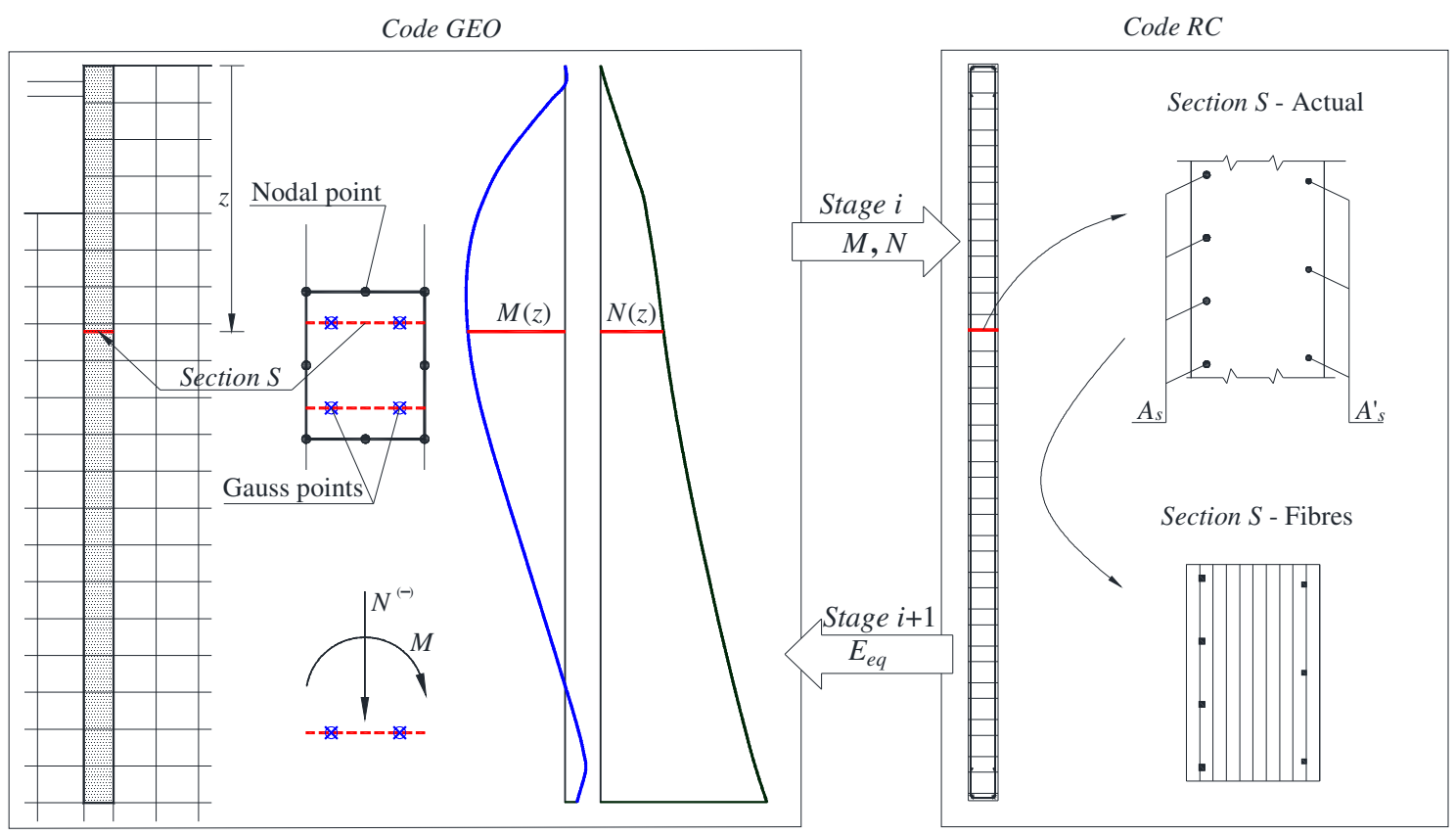

Figure 1. Interaction between the geotechnical model and the structural model. 


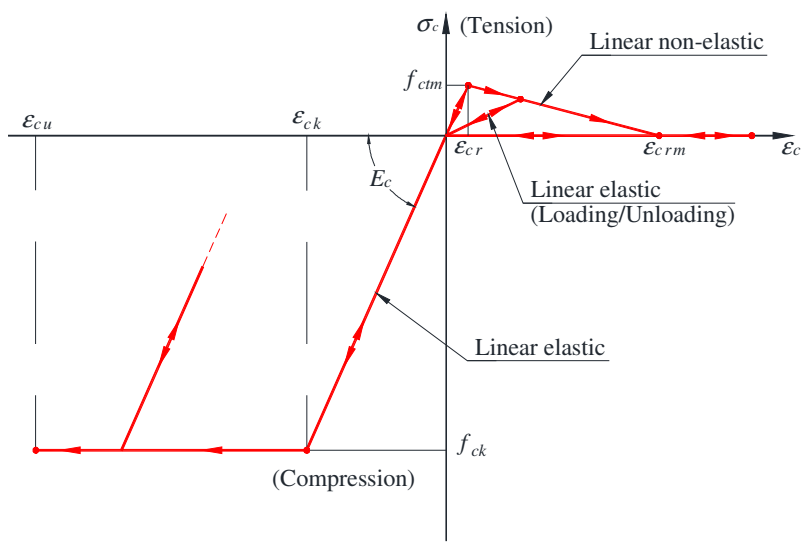

(a)

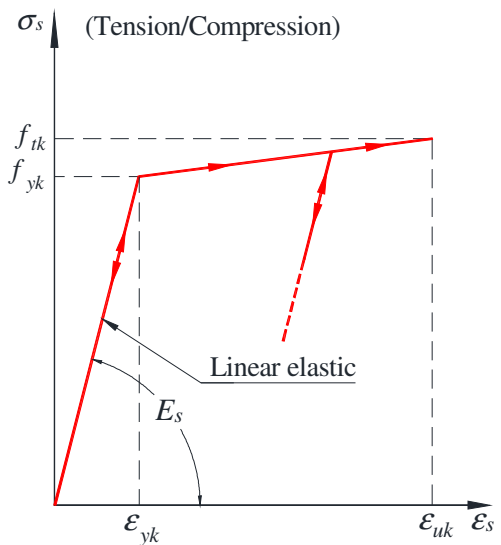

(b)

Figure 2. Constitutive law assumed in Code RC: (a) concrete; (b) steel.

The use of the above mentioned tension stiffening model for the concrete under tension results in a relation between the curvature of the section and the bending moment as presented in Figure 3.

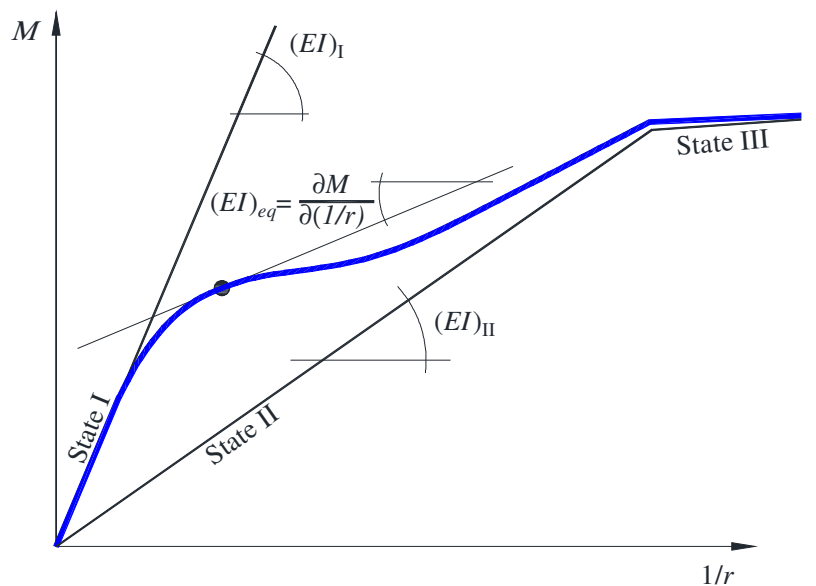

Figure 3. Relationship between curvature and bending moment at a reinforced concrete section evidencing the phenomenon of tension stiffening.

Three states (I, II and III) are denoted close to straight lines, whose inclination has the meaning of a bending stiffness. The so-called State I corresponds to the uncracked section; State II corresponds to a cracked section neglecting the tensile strength of concrete; State III corresponds to a situation where the tensile strength of both concrete and reinforcement steel is exhausted and the bending stiffness becomes residual (formation of a plastic hinge). The curve depicted in the figure reveals a smooth transition between states I and II as a result of the adopted tension stiffening model, which represents an approximation to the "real" behaviour.

Creep and shrinkage is not considered in this model.

\subsection{Interaction between Codes GEO and RC}

As shown in Figure 1, in Code GEO each horizontal pair of Gauss points of a finite element belonging to the retaining wall defines a section. Therefore, the $n$ two-dimensional finite elements of the retaining wall in Code GEO give rise to $2 n$ horizontal sections to be analysed by Code RC.

In a preliminary stage (Phase 0), Code RC computes the initial elastic bending stiffness of all sections, on the basis of the respective concrete and steel reinforcement, whereas Code GEO generates the at-rest state of stress. For each of the following stages, Code GEO conveys to Code RC the values of the incremental stresses in each section of the wall. Then, Code RC establishes the internal equilibrium of the sections taking into consideration the constitutive laws and the characteristics of concrete and steel, calculating the state of stress and strain for each individual fibre; this process leads to the calculation, for each section, of the new bending stiffness affected by cracking. The stiffness obtained by the adjustment of the deformation modulus, $E_{\text {eq }}$, is then introduced in Code GEO, to be used in the next construction stage.

\section{EXAMPLE OF APPLICATION}

\subsection{Geometry of the problem and basic input data}

Figure 4 represents a cross section of the numerical case study performed to illustrate the application of the proposed methodology: a symmetric excavation, $9 \mathrm{~m}$ deep and $40 \mathrm{~m}$ wide, supported by a reinforced concrete diaphragm wall, $0.8 \mathrm{~m}$ thick, propped at the top.

The ground is composed by a soft to medium clay deposit until a depth of $19 \mathrm{~m}$, underlain by a stiff clay layer and, at $25 \mathrm{~m}$ depth, by bedrock. The wall tip penetrates $1 \mathrm{~m}$ in the stiff clay.

The analyses with Code GEO were performed under plane strain conditions and in total stresses, assuming undrained behaviour of both clays. The constitutive model adopted for the soils was a classic Tresca elastic-perfectly plastic law. Table 1 summarizes the geotechnical parameters of the analyses. 
A similar constitutive law was adopted for the soil-wall interface, whose strength was taken equal to $2 / 3$ of the undrained shear strength of the soil at the same depth, being mobilized for a tangential relative displacement of $1 \mathrm{~mm}$.

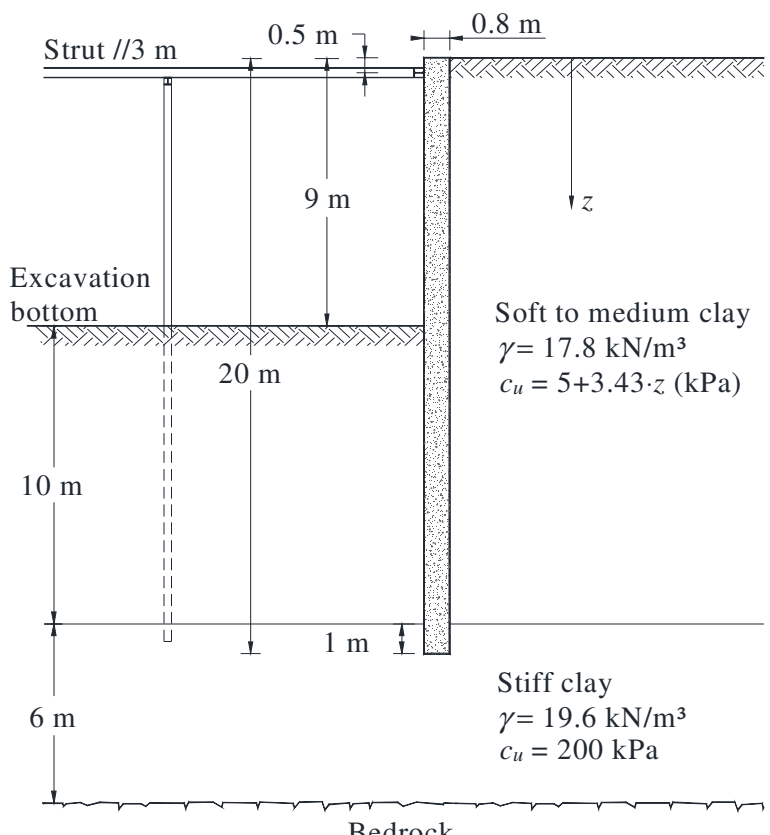

Figure 4. Example of application: cross section of the excavation and of the retaining structure.

Geotechnical parameters introduced in Code GEO.

\begin{tabular}{cccccc}
\hline Soil & $\begin{array}{c}\gamma \\
\left(\mathrm{kN} / \mathrm{m}^{3}\right)\end{array}$ & $K_{0}$ & $\begin{array}{c}c_{u} \\
(\mathrm{kPa})\end{array}$ & $\begin{array}{c}E_{u} \\
(\mathrm{MPa})\end{array}$ & $v$ \\
\hline $\begin{array}{c}\text { Soft / medium } \\
\text { clay }\end{array}$ & 17.8 & 0.6 & $5+3.43 \cdot z(\mathrm{~m})$ & $400 \cdot c_{u}$ & 0.49 \\
$\begin{array}{c}\text { Stiff clay } \\
\text { Stal }\end{array}$ & 19.6 & 0.7 & 200 & $400 \cdot c_{u}$ & 0.49 \\
\hline
\end{tabular}

Figure 5 shows the finite element mesh used in Code GEO, formed by 1092 eight-node isoparametric finite elements to represent the soil (1052 elements) and the wall (40 elements), 80 six-node joint elements to represent the soil-wall interface plus 4 six-node joint elements in the stiff clay and 1 two-node bar-element to simulate the prop level.

The left boundary was placed at the plane of symmetry of the excavation, whereas the right boundary was assumed $50 \mathrm{~m}$ behind the face of the excavation. The lower boundary was assumed at the top of bedrock.

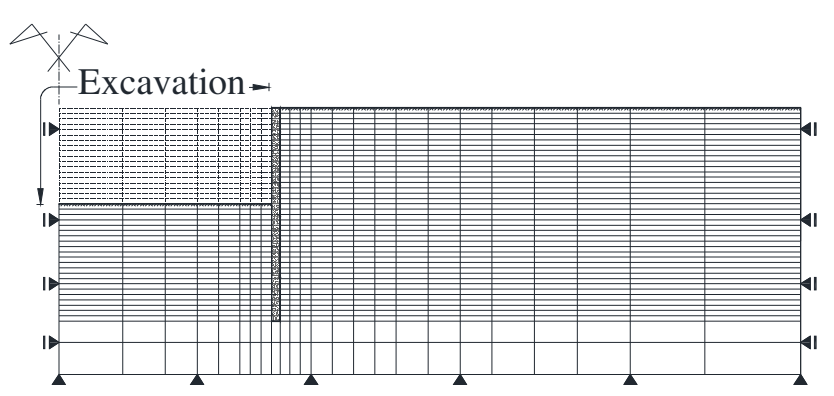

Figure 5. Finite element mesh for Code GEO.

It was admitted that the installation of the diaphragm wall does not alter the at-rest state of stress. The excavation was simulated by 18 stages of $0.5 \mathrm{~m}$ each; after the two first excavation stages, corresponding to $1.0 \mathrm{~m} \mathrm{depth}$, the level of props is installed $(0.5 \mathrm{~m}$ from the top of the wall) with no pre-stress.

The level of props, assumed as linear elastic, corresponds to HEB320 steel sections, spaced $3.0 \mathrm{~m}$ on the longitudinal direction. Their effective axial stiffness was adopted equal to $50 \%$ of the theoretical stiffness, to account for eventual imperfections and gaps at the prop-wall interface.

With such input data and assumptions, a preliminary analysis with Code GEO has been performed assuming the diaphragm wall as linear elastic, with a bending stiffness corresponding to the actual concrete section ( $0.8 \mathrm{~m}$ thick). The maximum positive and negative bending moments obtained from this analysis were selected to calculate the steel reinforcement at both wall faces, considering a partial safety factor of 1.35 for permanent actions in the safety check for ultimate limit states, as recommended by Eurocode 7 .

Table 2 summarizes the concrete and steel parameters adopted for steel reinforcement design and later introduced in Code RC. It is assumed that the steel reinforcements computed at the sections with maximum bending moments are kept constant along the full height of the wall.

Table 2. Structural parameters introduced in Code RC.

\section{Concrete}

Strength class: $\mathrm{C} 30 / 37$

Characteristic value of compressive strength: $f_{c k}=30 \mathrm{MPa}$

Mean value of axial tensile strength: $f_{c t m}=2.9 \mathrm{MPa}$

Modulus of elasticity: $E_{c}=33 \mathrm{GPa}$

Steel

Strength class: S400

Characteristic value of yield strength: $f_{y k}=400 \mathrm{MPa}$

Modulus of elasticity: $E_{s}=200 \mathrm{GPa}$

Steel reinforcement at the front face:

Steel reinforcement at the back face:

$$
A_{s}=80.4 \mathrm{~cm}^{2} / \mathrm{m}(10 \phi 32 / \mathrm{m})
$$

$A^{\prime}{ }_{s}=25.1 \mathrm{~cm}^{2} / \mathrm{m}(8 \phi 20 / \mathrm{m})$

As shown in Figure 6, the 40 finite elements that represent the wall in Code GEO lead to 80 horizontal sections to be analysed by Code RC. Each 
section is divided into 40 equal thickness concrete fibres, parallel to the neutral axis, plus a number of square shaped fibres, with an area equivalent to that of the steel rods, and placed at the same relative position in the actual section.

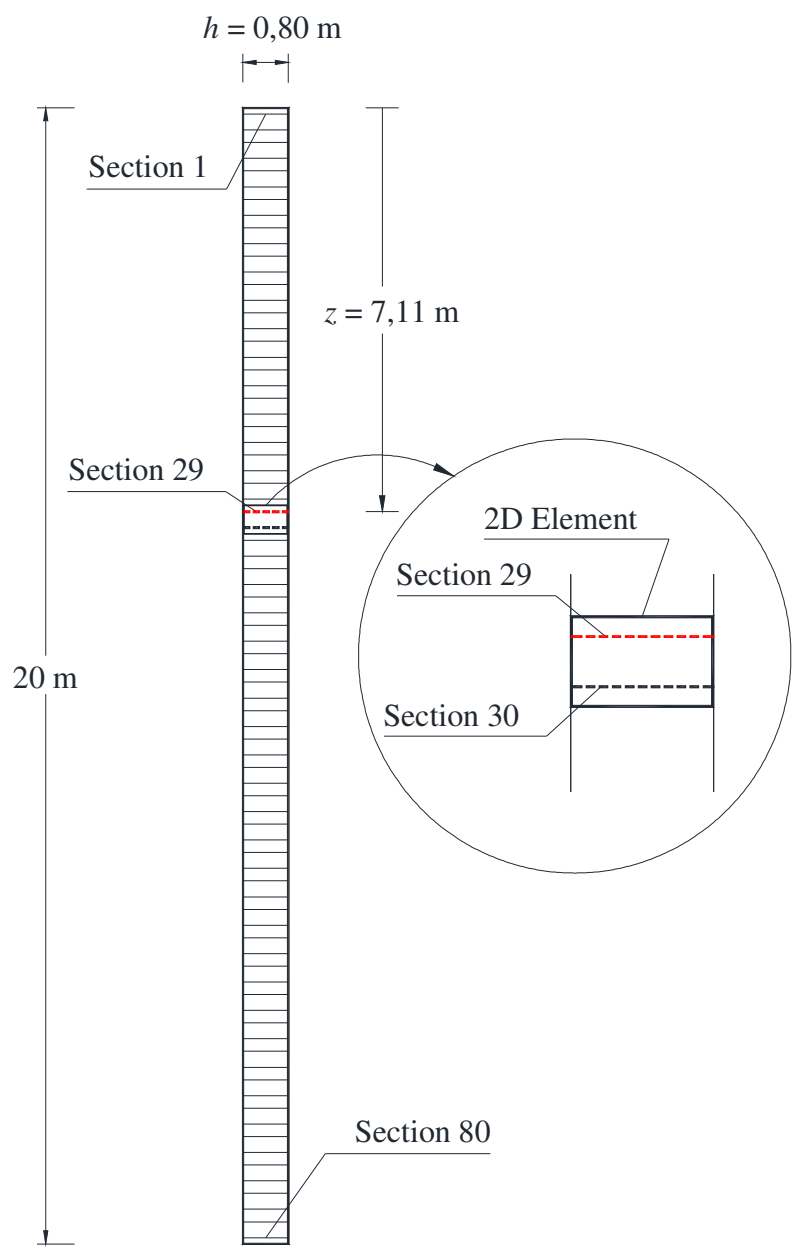

(a)
The geometrical and mechanical parameters (for concrete and steel) considered for the diaphragm wall correspond to an initial elastic bending stiffness, $(E I)_{0}$, of $1614 \mathrm{MNm}^{2} / \mathrm{m}$.

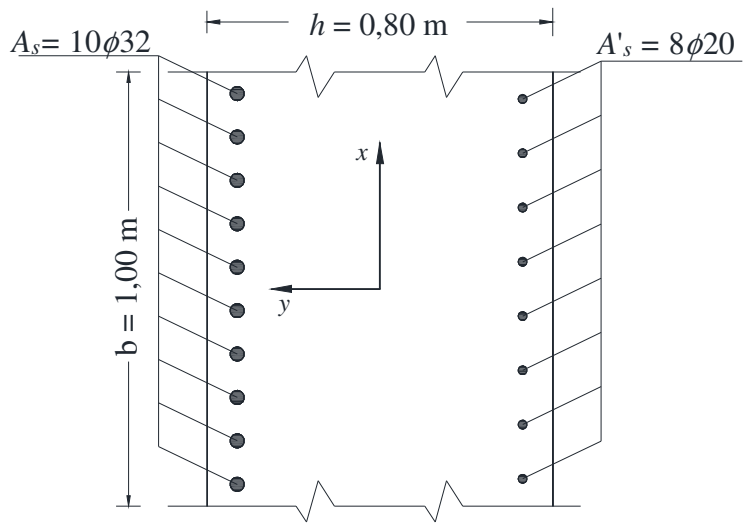

(b)

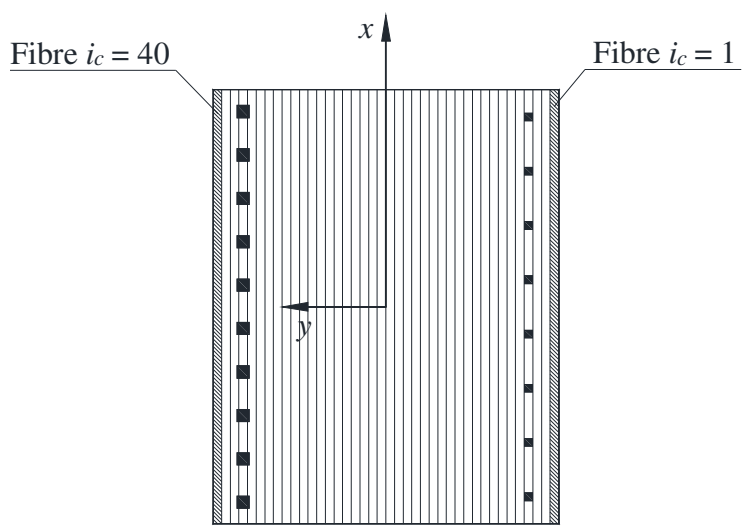

(c)

Figure 6. Code RC model of concrete wall: (a) vertical discretization in 80 sections; (b) actual reinforced concrete section; (c) discretization of the section in concrete and steel fibres.

\subsection{Discussion of results}

Two analyses have been performed, just differing with regard to the behaviour assumed for the diaphragm wall material:

i) analysis A, with the linear elastic wall, thus with constant bending stiffness;

ii) analysis $\mathrm{B}$, considering the nonlinear behaviour of the reinforced concrete, with the bending stiffness of each section adjusted, stage by stage, to take into account the cracked part of the section.

Naturally, in analysis A only the model GEO is used, whereas in analysis B the interaction between models GEO and RC is applied. Both analyses, at their start, assume the same elastic wall bending stiffness, $(E I)_{0}$.
Figure 7 includes the bending moment and axial force diagrams, as well as the horizontal wall displacement, at the completion of the excavation for both analyses. The position of section 29 at the depth of $z=7.11 \mathrm{~m}$, where maximum positive bending moment occurs, is also indicated; this section will be latter object of a detailed analysis.

The analysis of the figure reveals that the consideration of nonlinearity induced by concrete cracking reduces the wall bending stiffness, which leads to lower wall bending moments (Figure 7a) and to higher wall deflections (Figure 7c).

On the other hand, it does not influence the distribution of axial forces (Figure $7 \mathrm{~b}$ ) because it does not affect the axial compressive stiffness. In this case, since there are no inclined and pre-stressed wall supports (such as anchors), axial stresses are small and just due to the self-weight of the wall and 
to the tangential stresses along both faces of the wall-soil contact.

The value of the strut load for analyses A and B are $293 \mathrm{kN} / \mathrm{m}$ and $267 \mathrm{kN} / \mathrm{m}$, respectively, at completion of the excavation.

For the case of analysis B, Figure $8 \mathrm{a}$ and $8 \mathrm{~b}$ illustrate the distribution of the wall bending

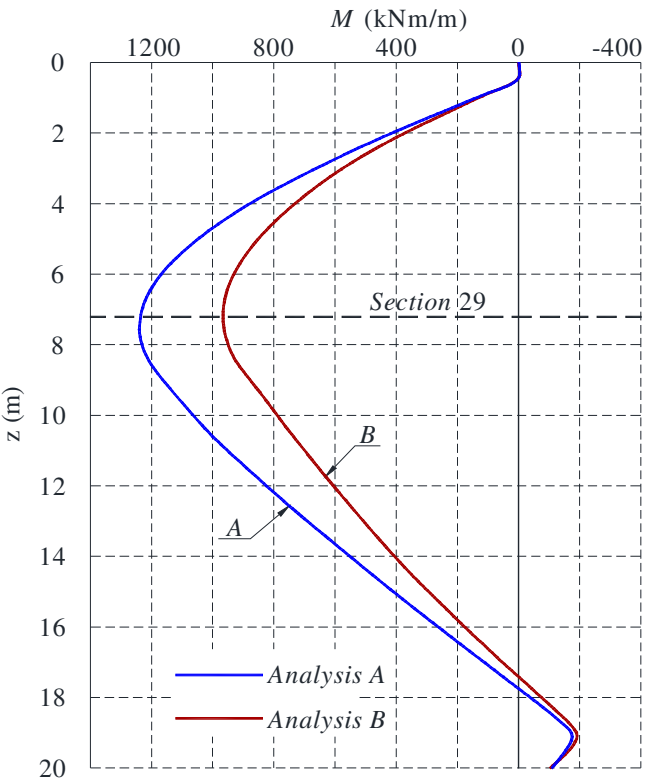

(a)

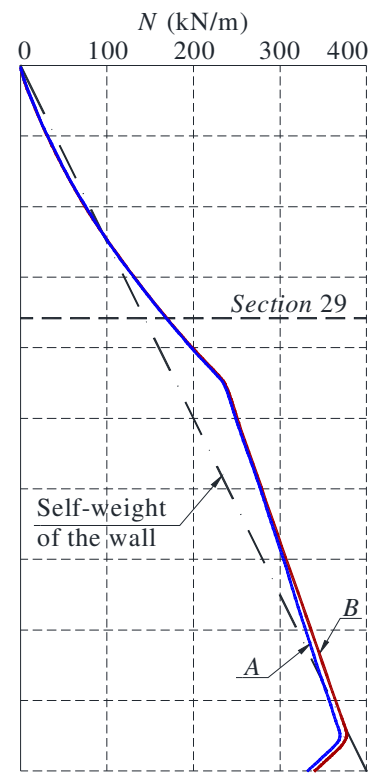

(b) moment and of the effective bending stiffness (expressed as a percentage of the initial elastic value) for stages 7 (excavation at $3.5 \mathrm{~m}$ depth, when first cracking occurs) and 18 (completion of the excavation).

Figure 7. Bending moments (a), axial forces (b) and horizontal displacements (c) of the wall at completion of the excavation, for analyses $\mathrm{A}$ and $\mathrm{B}$.

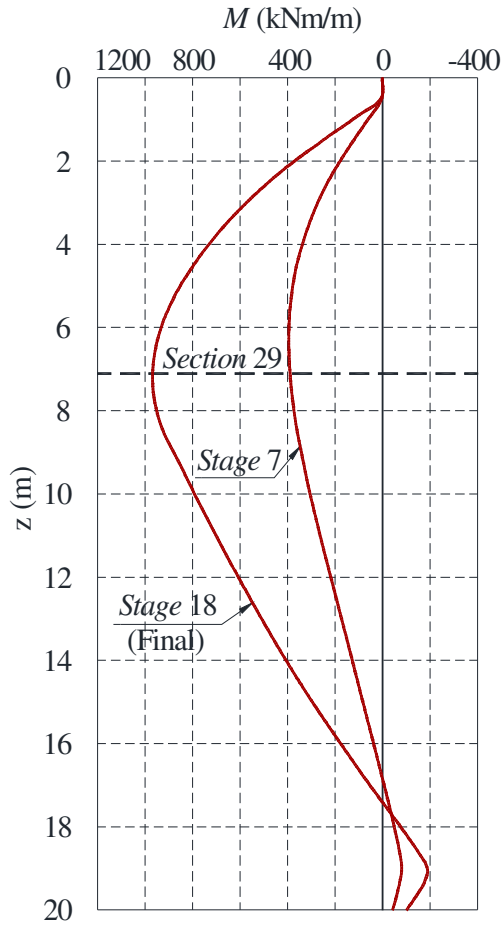

(a)

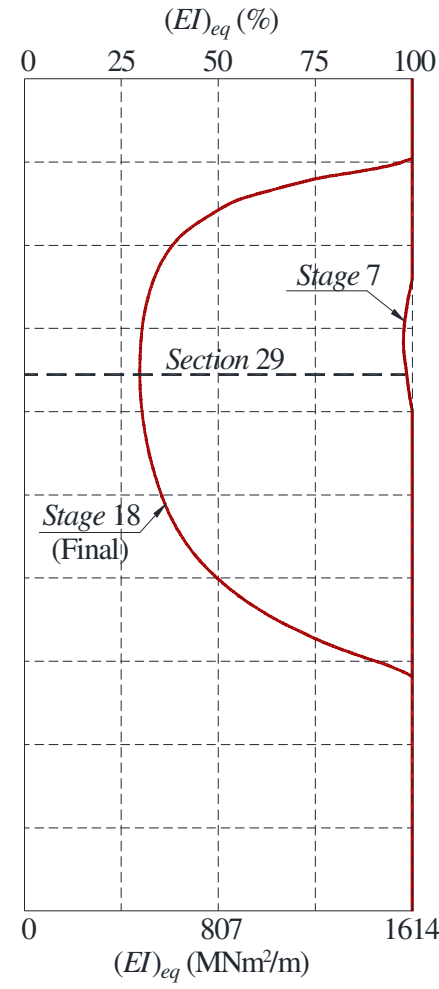

(b)

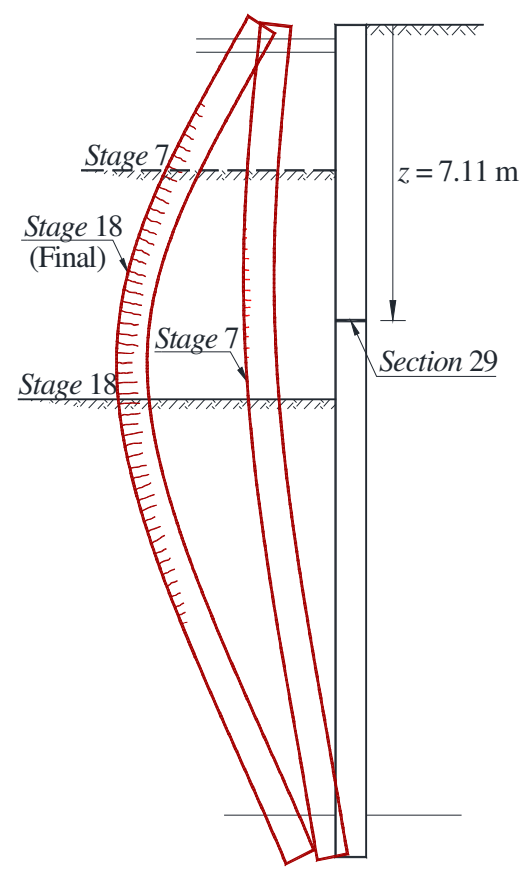

(c)

Figure 8. Wall bending moments (a), effective wall bending stiffness (b) and wall deflections (c) from analysis B (nonlinear behaviour of concrete) for stages 7 and 18 (final).

As shown by the figure, at stage 18 the bending stiffness suffered a reduction of about $70 \%$ along $1 / 3$ of the entire wall height. Moreover, approximately $60 \%$ of the wall sections suffered stiffness reduction 
by cracking at this final stage. The distribution of cracking together with the deflections of the wall may be observed in Figure 8c, for stages 7 and 18, as well.

For the same analysis B, Figure 9a presents the distribution of normal strain and stress in section 29, for stages 7 and 18 (negative values are adopted for compression). In the figure, fibre 1 is adjacent to the back wall face whereas fibre 40 is adjacent to the front face.

It can be observed that for stage 7, when cracking is still negligible, the distribution is almost linear, with the neutral axis (null values of stress and strain) at the centre of rigidity of the section. A quite distinct situation is obtained for stage 18 , with more than $60 \%$ of the section under tensile stress, giving rise to cracks and to a pronounced reduction of the bending stiffness as previously referred, as well as a change on the neutral axis position.
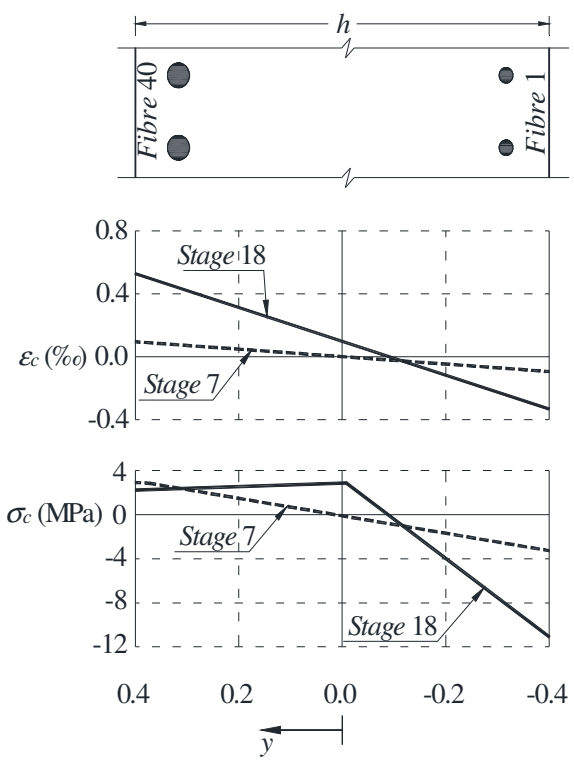

(a)

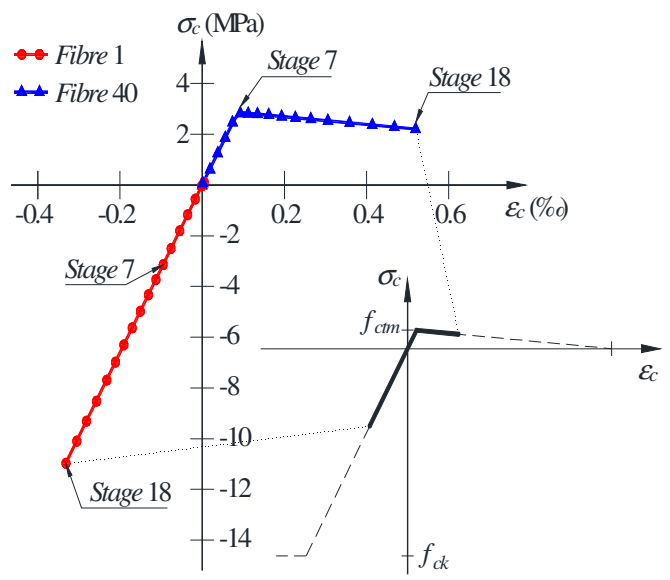

(b)

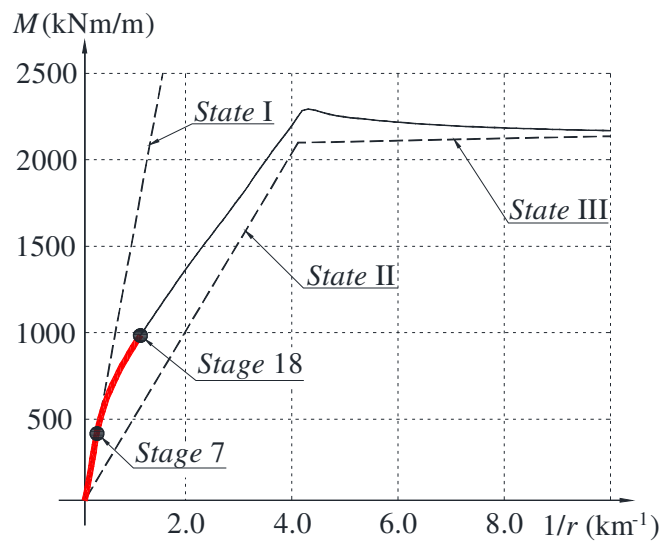

(c)

Figure 9. Results from analysis B for concrete section 29: (a) distribution of normal strain and stress, for stages 7 and 18; (b) normal stress versus normal strain for the extreme fibres, for all construction stages; (c) positions of stages 7 and 18 in the complete curvature versus bending moment diagram.

The evolution of the normal stress at the two extreme fibres is illustrated in Figure 9b. Until stage 7 is reached, a linear evolution is observed, with equal values of compressive and tensile stress, the latter reaching the respective strength approximately at this stage. The start of cracking induces a radical change in that evolution with tensile stresses experiencing a progressive reduction, explained by the so-called tension stiffening phenomenon. Contrarily, the evolution of compressive stresses beyond stage 7 maintains the same initial linear trend, since the value of compression at the completion of excavation (stage 18) is just about $37 \%$ of $f_{c k}$, as can be observed in Figure $9 \mathrm{~b}$.

Finally, Figure 9c illustrates the location of stages 7 and 18 in the complete curvature versus bending moment diagram. It can be observed that stage 7 is still very close to State I, whereas stage 18 is about at midway from States I and II, which induces a drop in the bending stiffness of about $70 \%$, as commented above. Nonetheless, since a common service situation is being analysed, even for this section of maximum bending moment, it can be seen that there is still a comfortable margin of safety with regard to the ultimate limit state.

Figure 9 contains only information about strain and stress in the concrete. With regard to steel reinforcement, the strain coincides with that of concrete in the same relative position in the section. The stress mobilized in the steel is always well below the respective yield strength.

\section{CONCLUSIONS}

The paper presents a methodology to incorporate the nonlinear behaviour of reinforced concrete in finite element analyses of deep excavations supported by concrete walls. This methodology is based on the 
interaction between two well-validated numerical models: one used for incremental analysis of geotechnical works (but assuming concrete as linear elastic) and the other used for nonlinear analysis of reinforced concrete structures taking into account the characteristics of the concrete and the steel reinforcement at each structural section.

This methodology was applied to the study of an excavation supported by a reinforced concrete diaphragm wall propped at the top. The consideration of nonlinearity induced by concrete cracking reduces the wall bending stiffness, and this leads to lower wall bending moments and to higher wall deflections. It was illustrated how this methodology allows assessing the distribution of normal strain and stress in both the concrete and the steel, as well as cracking, in a given section of the retaining wall.

The results obtained are encouraging. The methodology seems to have great potential for the analysis of more complex problems, such as multi-propped walls or to the study of plastic hinge development, simulating the occurrence of ultimate limit states in certain sections of the retaining wall.

\section{AKNOWLEDGEMENTS}

This work was financially supported by: Project POCI-01-0145-FEDER-007457 - CONSTRUCT Institute of R\&D In Structures and Construction funded by FEDER funds through COMPETE2020 Programa Operacional Competitividade $e$ Internacionalização (POCI) - and by national funds through FCT - Fundação para a Ciência $e$ a Tecnologia; and Doctoral Scholarship SFRH/BD/72454/2010 through FCT.

The careful review of the paper by the Colleagues José Marques and Paulo Pinto is gratefully acknowledged.

\section{REFERENCES}

Almeida e Sousa, J., Negro, A., Matos Fernandes, M. \& Cardoso, A.S. 2011. Three-dimensional nonlinear analyses of a metro tunnel in Sao Paulo porous clay, Brazil. Journal of Geotechnical and Geoenvironmental Engineering, ASCE 137(4):376-84.

Bazant, Z.P. \& Parameshwara, D.B. 1977. Prediction of hysteresis of reinforced concrete members. Journal of Structural Engineering, ASCE 103(1):153-167.

Burlon, S., Mroueh, H. \& Shahrour, I. 2013. Influence of diaphragm wall installation on the numerical analysis of deep excavation. International Journal for Numerical and Analytical Methods in Geomechanics, (37):1670-1684.

Chen, W.F. \& Shoraka, M.T. 1974. Analysis and design of reinforced columns under biaxial loading. Proceedings of Symposium on Design and Safety of Reinforced Concrete Compression Members, IABSE (16):187-195.
Clough, G.W. \& Tsui, Y. 1974. Performance of tied-back walls in clay. Journal of Geotechnical Engineering, ASCE, 100(12):1259-1273.

Cohn, M.Z. \& Ghosh, S.K. 1972. The flexural ductility of reinforced concrete sections. IABSE (32):53-83.

Crisfield, M. 1997. Non-linear Finite Element Analysis of Solids and Structures. John Wiley \& Sons, vol. 2, New Jersey, USA.

Dong, Y.P., Burd, H.J. \& Houlsby, G.T. 2016. Finite-element analysis of a deep excavation case history. Géotechnique 66(1):1-15.

EN 1997-1. 2004. Eurocode 7: Geotechnical Design - Part 1: General Rules, CEN.

Ferraz, M.A.C. 2010. Models for the Evaluation of the Structural Behaviour of Bridges. Ph.D thesis (in Portuguese), Univ. Porto.

Finno, R.J. \& Harahap, I.S. 1991. Finite element of HDR-4 excavation. Journal of Geotechnical Engineering, ASCE 117(10):1590-1609.

Finno, R.J., Arboleda-Monsalve, L. \& Sarabia, F. 2015. Observed Performance of the One Museum Park West Excavation. Journal of Geotechnical and Geoenvironmental Engineering, ASCE 141(1):1-11.

Hashash, Y.M., Song, H. \& Osouli, A. 2011. Threedimensional inverse analyses of deep excavation in Chicago clays. International Journal for Numerical and Analytical Methods in Geomechanics (35):1059-1075.

Liu, G.B., Jiang R.J., Ng, C.W. \& Hong, Y. 2011. Deformation characteristics of a $38 \mathrm{~m}$ deep excavation in soft clay. Canadian Geotechnical Journal 48(12):1817-1828.

Matos Fernandes, M. 2010. Deep urban excavations in Portugal: practice, design, research and perspectives. Soils and Rocks 33(3):115-142.

Matos Fernandes, M., Cardoso, A., Trigo, J. \& Marques, J. 1993. Bearing capacity failure of tied-back walls - a complex case of soil-wall interaction. Computers and Geotechnics 15(2):87-103.

Mohr, S. \& Bairán, J.M. 2010. A frame element model for the analysis of reinforced concrete structures under shear and bending. Engineering Structures 32(12):3936-3954.

Ng, C.W., Hong, Y., Liu, G.B. \& Liu, T. 2012. Ground deformations and soil-structure interaction of a multi-propped excavation in Shanghai. Géotechnique 62(10):907-921.

Schafer, R. \& Triantafylidis, T. 2006. The influence of the construction process on the deformation behaviour of diaphragm walls in soft clayey ground. International Journal for Numerical and Analytical Methods in Geomechanics (30):563-576.

Zdravkovic, L, Potts, D.M. \& St. John, H.D. 2005. Modelling of a 3D excavation in finite element analysis. Géotechnique 55(7):497-513. 